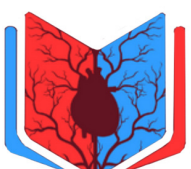

Published By : IVAA

the Indonesian Vascular Access Association

\section{Arteriovenous shunt as the best hemodialysis access in Chronic Kidney Disease (CKD) patients: a literature review}

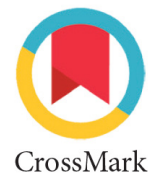

CrossMark
'Setio Husodo Hospital, Kisaran,

Indonesia

${ }^{2}$ Faculty of Advance Technology and Multidisciplinary, Universitas Airlangga Hospital, Surabaya, Indonesia

*Corresponding to:

Niko Azhari Hidayat; Faculty of Advance Technology and Multidisciplinary,

Universitas Airlangga Hospital, Surabaya, Indonesia;

niko-a-h@fk.unair.ac.id

Received: 2021-04-26

Accepted: 2021-06-02

Published: 2021-06-16

\author{
Abed Nego Okthara Sebayang ${ }^{1}$, Niko Azhari Hidayat ${ }^{2 *}$
}

\section{ABSTRACT}

Arteriovenous Shunt (AV Shunt) is a minor surgical operation that connects (creating anastomoses) the arteries and veins in the arm or other body part for the purpose of making connection access for hemodialysis. AV shunt is the primary choice in establishing vascular access for hemodialysis in patients with Chronic Kidney Disease (CKD). Therefore, this study aims to review the arteriovenous shunt as a hemodialysis access option in CKD patients. The literature study was conducted by searching various written sources, whether in the form of books, archives, articles and journals, or documents relevant to the problem being studied. The mortality rate after AV shunt is $0 \%$, even though it still has postoperative complications. Based on the location of the operation, making the AV shunt is prioritized on the distal part that is not dominant to minimize the damage to the AV shunt. The location of the wrist, namely the brachiocephalic, is a top priority in making an AV shunt because it has many advantages. AV shunt is the primary choice of vascular access for hemodialysis in patients with chronic kidney disease. It is hoped that through the AV shunt, the life expectancy of patients with CKD can be increased, and patients with CKD must receive support from other disciplines such as interns, psychologists, and the patient's family.

Keywords: artery, Arteriovenous Shunt, hemodialysis, venous

Cite This Article: Sebayang, A.N.0., Hidayat, N.A. 2021. Arteriovenous shunt as the best hemodialysis access in Chronic Kidney Disease (CKD) patients: a literature review. Journal of Indonesia Vascular Access 1(1): 1-3. D0I : 10.51559/jinava.v1i1.6

\section{INTRODUCTION}

The kidney is an organ located retroperitoneally in the abdominal wall on the right and left of the vertebral column at the level of the vertebrae T12 to L3. ${ }^{1}$ The kidneys have essential functions, such as excretion and secretion of waste metabolites out of the body. If the physiological function of the kidney decreases or does not function at all, then conservative treatment such as diet, limiting fluid consumption, drugs, etc., will not give significant results in that condition; thus, hemodialysis should be done immediately. This condition is called Chronic Kidney Disease (CKD). ${ }^{2}$

CKD patients of any etiology require replacement therapy for their impaired renal function. Replacement therapy required by patients with chronic kidney disease must replace the kidneys' excretory, secretory, and endocrine functions because in $\mathrm{CKD}$, these three functions are deteriorating. Replacement therapy can be broadly divided into kidney transplantation and dialysis., ${ }^{2,3}$ Successful kidney transplant will replace all damaged kidney function, while dialysis is further divided into peritoneal dialysis and vascular dialysis. Vascular dialysis is further divided into several types, such as a double-lumen shortterm catheter, long term double-lumen catheter, arteriovenous (AV) shunt, and arteriovenous graft. ${ }^{4}$

Hemodialysis is a process that involves diffusion and ultrafiltration to remove certain elements from the blood by taking advantage of the difference in the diffusion rate of blood as it passes through a semipermeable membrane. ${ }^{5}$ Hemodialysis is performed by pumping the patient's blood and flowing it to the blood compartment bordered by an artificial semipermeable membrane with a dialysate compartment. Dialysate fluid has an electrolyte composition similar to the normal serum, which does not contain metabolic waste and does not contain pyrogens. Blood fluids and dialysate will experience a change in concentration from low to reaching the same solute concentration, this process is called diffusion. $^{5,6}$ Meanwhile, ultrafiltration is the movement of water from the blood compartment to the dialysate compartment by increasing the negative hydrostatic pressure in the dialysate compartment. $^{5}$

The amount and pressure of blood flowing to the dialysis machine must be adequate. Therefore, we need a special access to hemodialysis, especially for routine hemodialysis. Generally, this access is formed in the arm by connecting the arm's vein to the radial or ulnar artery. This will cause a shunt of blood flow from the arteries to the veins to enlarge and experience epithelialization. ${ }^{4}$ The location 
of AV shunt used in hemodialysis varies widely. In Indonesia, surgeons used many access for hemodialysis, such as femoral, which used as much as $2 \%$, jugular access was used in $1 \%$ of hemodialysis cases, and subclavian access was used by $3 \%$. The majority of the access used is vascular access. ${ }^{7,8}$ Therefore, this review will discuss the potential of $\mathrm{AV}$ shunt as the best hemodialysis access in CKD patients.

\section{METHOD}

The method used in this research is literature study. The literature study conducted by the author is to search for literature using ScienceDirect and literature used indexed by Scopus and Scimago. These various written sources are books, archives, articles, journals, and documents that are relevant to the problem under study. So that the information obtained from this literature study is used as a reference to strengthen existing arguments. In this study, eleven reference sources consisting of various journals related to arteriovenous shunts were used as access to hemodialysis in patients with chronic kidney disease

\section{GENERAL PERSPECTIVE OF AV SHUNT}

AV Shunt is an operation to connect the arteries and veins to the arm or other body part to make the connection access for hemodialysis. ${ }^{910}$ The AV shunt is the gold standard in establishing vascular access for hemodialysis in patients with chronic kidney disease. AV shunts are designed to improve the effectiveness of dialysis function and reduce the risks and complications of other vascular access. ${ }^{11}$ The AV shunt or the Cimino shunt causes higher pressure to flow into the veins connected to cause thrills or bruits on auscultation. The vein that has become larger allows easy access by a puncture into the vessel for hemodialysis.

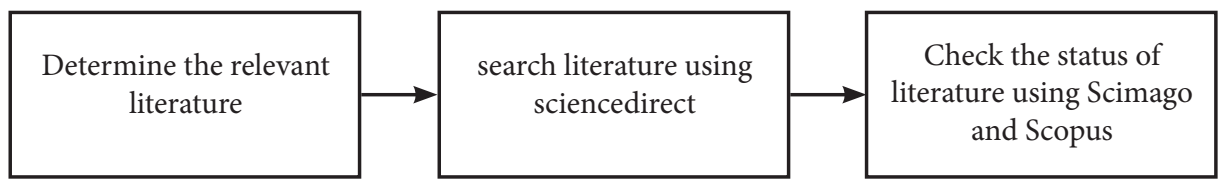

Figure 1. Flowchart of the literature searching
Without adequate access like this, routine hemodialysis procedures performed by veins will not be able to withstand repeated dialysis needle punctures. ${ }^{12,13}$

In principle, the creation of an $\mathrm{AV}$ shunt is initiated from the arteries and veins in the more distal part of the arm and the arm that is not dominant. This is indicated so that there are still arterial and venous reserves in the proximal part when there is failure to access the distal part. ${ }^{3,5}$ If this is not possible, an AV shunt can be performed proximal to the non-dominant arm and finally to the proximal to the dominant arm. The wrist is a top priority in AV shunt manufacture because it has many advantages. Arteries and veins that are commonly used are the radial artery and cephalic vein. Another name for this anastomosis is radiocephalic fistula..$^{5,14,15}$

$\mathrm{AV}$ shunt can also be made on the brachial artery with the cephalic vein. This type of anastomosis is highly recommended for patients with DM due to superiority of the flow generated and its maturation rate. Although the results are very good with this method, in this type of fistula, there is a very frequent incidence of "steal syndrome", especially if the arteriotomy is very long. This type of fistula can also create a loss of the remaining forearm area for future access creation., ${ }^{9,12}$ The choice of making a brachiocephalic AV shunt is usually made if the results of the duplex ultrasound examination do not find a suitable cephalic vein in the wrist area. For example, where the cephalic vein of the left wrist has a diameter up to $0.10 \mathrm{~cm}$ and non-compressible, a more proximal area (brachiocephalic fistula) is chosen. Brachiocephalic fistula has a low failure has a good long-term patency rate.

\section{PROCEDURE OF AV SHUNT}

The AV Shunt procedure is performed using four operating techniques, namely side to side, side to end, end to side and rate, which is estimated at about $10 \%$, and

end to end. The most popular technique that is used today is from side to side and end to end. ${ }^{3}$ Based on its location, some of the locations selected for the av shunt procedure are radiocephalic fistula, brachiocephalic fistula, brachiobasilic fistula and ulnar-basilic fistula. Radiocephalic fistula is the main choice of AV shunt procedure because it technically has advantages such as less blood flow compared to fistula. other so that the risk of heart failure ischemia is also lower. ${ }^{4}$

Before making the AV shunt, the general condition should be improved, such as double lumen hemodialysis and blood transfusion, so the patient does not experience fluid overload, hemoglobin $(\mathrm{Hb})$ increases, and urea decreases. The primary maturation of the brachiocephalic fistula takes 8-12 weeks. This causes the hemodialysis procedure through this newly-form access cannot be carried out immediately after surgery until the maturation of the internal AV shunt occurs. The operation steps for making AV shunt access are as follows. ${ }^{9,10}$ The first stage is disinfection. In the operation area, sterile disinfection was carried out with an antiseptic solution, after which the area of the operation was limited by using sterile linen/cloth. ${ }^{5,10}$ The second stage is anesthesia. The patient was subjected to local anesthesia using $1 \%$ lidocaine with added epinephrine to reduce bleeding. In addition, block anesthesia can also be considered because it has the advantage of inhibiting the sympathetic nervous system so that vasospasm does not occur. ${ }^{5,9,10}$

Furthermore, in the area of operation that has been determined using ultrasound guidance, a longitudinal or transverse incision is performed. If there is bleeding at the incision, the bleeding is controlled. The skin flap is lifted laterally to reveal the cephalic vein. The cephalic vein is then set aside $3-4 \mathrm{~cm}$ to avoid trauma to the radial nerve., ${ }^{5,9,10}$ The deep fascia layer of the forearm is then opened transversally to find the radial artery to the lateral side of the flexor carpi radialis muscle. The radial artery is then set aside to perform anastomosis end to end, end to side, or side to side., ${ }^{5,910}$ The thread is placed in the artery that is set aside. Incision of the radial artery using a knife blade then made according to the diameter of the cephalic vein that has been cut. Then performed 
anastomosis between the cephalic vein and the radial artery using a $6-0$ or $7-0$ monofilament thread. ${ }^{5,9,10}$ The final stage was postoperative bleeding care, then the wound was surgically closed by suturing the skin, bandaging the arm according to the procedure, and performing routine control at the clinic. ${ }^{5,9,10}$

\section{RESULT AND POSSIBLE COMPLICATION OF AV SHUNT}

The connection made with the AV shunt will rapidly increase blood flow. This results in enlargement of the arteries and veins. In addition, there is also a thickening of the walls, especially in the veins. After the AV shunt surgery, the blood flow rate increases. Blood flow increased from 21.6 $\pm 20.8 \mathrm{ml} / \mathrm{min}$ to $208 \pm 175 \mathrm{ml} / \mathrm{min}$ after surgery. This flow can increase to 600 to $1200 \mathrm{ml} / \mathrm{min}^{3,5,16}$ The following process is an increase in wall shear stress and pressure on the vein walls caused by increased blood flow in the veins. Wall shear stress is a friction pressure produced by blood against the walls of the blood vessels in the same direction as the flow. Then, there will be changes in the cell and extracellular structure of the blood vessels. ${ }^{12,17}$

The effectiveness of using AV Shunt is very good when compared to other accesses because it uses access that comes from the patient's own body. In general, if the blood vessels have never been manipulated such as puncture, usually the av shunt manufacture never fails. Failure usually occurs when the diameter of the blood vessels is small or difficult to find. In addition, failure may arise due to surgeon factors and the accuracy of the vascular anastomosis. $^{3-6}$

Many complications can occur within AV shunt surgery, such as shunt failure, stenosis in the proximal venous leg (48\%), thrombosis (9\%), aneurysm (7\%), heart failure due to shunt too large (greater than $20 \%$ of cardiac output), arterial steal syndrome and distal ischemia (1.6\%), distal venous hypertension from shunt swelling, hyperpigmentation, skin induration, and occasional ulceration. ${ }^{8,13,14,17}$ But after all, the mortality rate after AV shunt is $0 \% .^{3,4,10}$ Death is generally due to comorbidities in these patients. After surgery, the patient can be sent home immediately and given education to protect the AV shunt area by not using it for IV-line insertion, pressure, or blood pressure measurements on the arm. Although it has postoperative complications, the mortality rate is $0 \%$, and its long-lasting use shows that av shunt is the best choice for access to dialysis to date. ${ }^{3,4,9,10,12,13}$

\section{CONCLUSION}

AV shunt or Cimino shunt is a gold standard procedure for CKD patients to connect (anastomose) arteries and veins to the arms or other parts of the body to make the connection access for hemodialysis. With the AV shunt, the vein will be able to withstand repeated dialysis needle puncture. It is hoped that through the AV shunt action, the life expectancy of patients with chronic renal failure can increase and must be supported by other disciplines such as internal medicine, psychologists, and the patient's family.

\section{ACKNOWLEDGMENTS}

We would to thank Niko A Hidayat For His comment and suggestions regarding the turbine engine analysis so that this article can be completed and can be useful to readers.

\section{DISCLOSURES}

\section{Funding}

This article do not use sponsorship funds and purely use author funds

\section{Conflict of Interest}

There is no conflict of interest in this article and all funding does not involve a specific sponsor or brand

\section{Author Contribution}

In this article, all authors are involved and take part in making the article. the first author contributed in drafting and designing this manuscript. the second author provides concepting, designing and supervising the manuscript.

\section{Ethical Statement}

Not applicable

\section{REFERENCES}

1. Mahadevan V. Anatomy of the kidney and ureter. Surg (United Kingdom). 2019;37(7):35964.
2. Charles C, Ferris AH. Chronic Kidney Disease. Prim Care - Clin Off Pract. 2020;47(4):585-95.

3. Trerotola SO. KDOQI Clinical Practice Guideline for Vascular Access 2019 Update: Kinder, Gentler, and More Important Than Ever. J Vasc Interv Radiol. 2020;31(7):1156-7.

4. Iqbal A, Baig A. Management of dialysis access. Off Endovasc Centers. 2019;(Cvc):253-63.

5. Wright FK. Principles of haemodialysis. Fourth Edi. Vol. 63, Nursing times. Elsevier Inc.; 1967. 5-7 p.

6. Dougherty MJ, Troutman DA, Maloni KC. Management of Difficult Dialysis Access Issues for Dialysis Patients. Adv Surg. 2019;53:83-101.

7. Dawoud D, Lok CE, Waheed U. Recent Advances in Arteriovenous Access Creation for Hemodialysis: New Horizons in Dialysis Vascular Access. Adv Chronic Kidney Dis. 2020;27(3):191-8

8. Schild AF, Perez E, Gillaspie E, Seaver C, Livingstone J, Thibonnier A. Arteriovenous fistulae vs. arteriovenous grafts: A retrospective review of 1,700 consecutive vascular access cases. J Vasc Access. 2008;9(4):231-5.

9. Lok CE, Huber TS, Lee T, Shenoy S, Yevzlin AS, Abreo K, et al. KDOQI Clinical Practice Guideline for Vascular Access: 2019 Update. Am J Kidney Dis. 2020;75(4):S1-164.

10. Ikizler TA, Burrowes JD, Byham-Gray LD, Campbell KL, Carrero JJ, Chan W, et al. KDOQI Clinical Practice Guideline for Nutrition in CKD: 2020 Update. Am J Kidney Dis. 2020;76(3):S1-107.

11. Agarwal AK, Haddad NJ, Vachharajani TJ, Asif A. Innovations in vascular access for hemodialysis. Kidney Int. 2019;95(5):1053-63.

12. De Rosa S, Samoni S, Villa G, Ronco C. Management of Chronic Kidney Disease and End-Stage Kidney Disease Patients in the Intensive Care Unit. Crit Care Nephrol Third Ed. 2017;1286-92.

13. Woodside KJ, Bell S, Mukhopadhyay P, Repeck KJ, Robinson IT, Eckard AR, et al. Arteriovenous Fistula Maturation in Prevalent Hemodialysis Patients in the United States: A National Study. Am J Kidney Dis. 2018;71(6):793-801.

14. Frankel A, Brown E, Wingfield D. Management of chronic kidney disease. $\mathrm{Br}$ Med $\mathrm{J}$. 2005;330(7499):1039-40.

15. Hsiao JF, Chou HH, Hsu LA, Wu LS, Yang $\mathrm{CW}$, Hsu TS, et al. Vascular changes at the puncture segments of arteriovenous fistula for hemodialysis access. J Vasc Surg. 2010;52(3):669-73.

16. Giele H, Barton R. Blood vessels. Disord Hand Vol 1 Hand Inj. 2015;1-21.

17. Levey AS, De Jong PE, Coresh J, Nahas M El, Astor BC, Matsushita $\mathrm{K}$, et al. The definition, classification, and prognosis of chronic kidney disease: A KDIGO Controversies Conference report. Kidney Int. 2011;80(1):17-28.

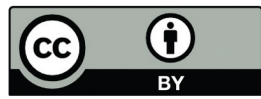

This work is licensed under a Creative Commons Attribution 